\title{
Spores Splashing Under Different Environmental Conditions: A Modeling Approach
}

\author{
A. Pielaat, L. V. Madden, and G. Gort
}

First and third authors: Wageningen Agricultural University, Dreijenlaan 4, 6703 HA Wageningen, the Netherlands; and second author: Ohio State University, Department of Plant Pathology, Wooster 44691.

Accepted for publication 3 August 1998.

Spores of many fungal plant pathogens are dispersed in rain splash droplets and consequently cause new infections within a crop $(4,9)$. Many of the most serious fungal diseases of crops in temperate and tropical climates are caused by pathogens with splashdispersed spores (6).

Experimental work on the dissemination of splash-dispersed pathogens has increased considerably in recent years $(7,12,17,20)$. A rain simulator often is used to study the dispersal process, and the effects of rain, canopy, surface, and pathogen properties are assessed $(3,10,19)$. For these experiments, an infected plant unit (e.g., fruit) is used as a point source, and the entire area receives a simulated rain. Resulting data sets on spore deposition contain information about the spatial spread from this point source for different environmental (e.g., rain intensity) and biological (e.g., crop density) conditions $(12,19)$. Up to now, these data sets have been used for the development of some descriptive models $(2,5)$. These models, however, only contain information on the dispersal gradients for the original experiment and cannot be used to predict spatial spread for different conditions. Therefore, a model was developed that incorporates the main physical mechanisms behind splash dispersal. Factors influencing the splashing process were incorporated in parameters underlying the spatial spread of spores from a point source. The model includes (i) a probability per time unit of a spore being splashed, (ii) a probability per splash of a spore being removed from the process, and (iii) a probability function for the distance a spore travels during a splash event. Since these are the main physical processes during splash dispersal influenced by environmental and biological conditions, their parameter values can be adapted for different circumstances.

In this paper, the main mechanisms behind splash dispersal are discussed and incorporated as separate terms in the model. In addition, it is shown how the total number of spores in the area surrounding the inoculum source changes from the start of the rain episode by derivation of a second model from the original. Finally, equations for the mean displacement and mean-squared distance displacement of spores from the original point source were determined. In particular, it is shown how the latter is used for characterizing and comparing dispersal.

The developed model was tested by comparing theoretical results with experimental results obtained with a rain simulator. Data sets were used for the splash dispersal of Colletotrichum acutatum conidia in relation to surface topography (22) and rain intensity (12).

Corresponding author: A. Pielaat; E-mail address: annemarie.pielaat@ztw.wk.wau.nl

Publication no. P-1998-0831-010

(C) 1998 The American Phytopathological Society

\section{MATERIALS AND METHODS}

For a better understanding of the model construction, an explanation of the experimental set-up used to assess spore dispersal is given.

At the start of the experiment, spore samplers are placed at several distances around an inoculum point source. The sampler consists of a petri dish, with a semiselective growth medium for Colletotrichum species, and a rain shield to prevent direct interception of rain (Fig. 1 in literature citation 22). The point source comprises infected strawberry fruit with sporulating lesions, and the entire area receives a rain of up to $46 \mathrm{~min}$ in duration. At several times during the rain, usually every $5 \mathrm{~min}$, splash droplets with spores are collected in the sampler for $1 \mathrm{~min}$. Petri dishes are then replaced and droplets are again collected. Petri dishes are incubated and fungal colonies are counted. Calibration studies show that $65 \%$ of spores deposited in the dishes germinate and form colonies (22).

Resulting data sets consist of the number of colonies per square centimeter per minute at several times and distances during rain episodes. Detailed information about the experimental set-up is given by Madden (9).

Data from two published experiments were considered here. In the first, dispersal (measured as colonies) was determined over three ground covers, plastic, soil, and straw, with rain intensities of 15 and $30 \mathrm{~mm} \mathrm{~h}^{-1}$ (22). In the second, dispersal was determined over soil for seven rain intensities, from 2 to $60 \mathrm{~mm} \mathrm{~h}^{-1}$ (12).

\section{THE MODEL}

Spatial spread of spores from a point source. Taking the above-described experimental results as a starting point, the model should represent the number of spores found at an arbitrary point on the surface at any time during a rain episode.

Suppose $M(t, x, y)$ stands for the number of spores found at a particular point, having coordinates $(x, y)$ in relation to the source at time $t$ during a rain episode. The number of spores entering a petri dish at some distance from the source per unit of time is assumed to be equal in all directions around the inoculum source, because of the lack of air movement in these studies. This means the number of spores will be homogeneously spread on any circle around the source. Now, the radius $r$ of any circle around the source can be expressed as $r=\sqrt{x^{2}+y^{2}}$. Henceforth, we use $N(t, r)$ to denote the number of spores found at any arbitrary point on a circle with radius $r$ around the source at time $t$ during the rain.

We first describe the spores on the surface at the start of the rain. At time $t=0$, the only spores are at the point source, $r=0$. Because, ultimately, we want to assess the distances spores travel from this starting point, we need a model expression in which spores at the source do not take any space themselves. The space that is occupied by an infected fruit is small relative to the distances 
traveled; thus, a "zero space" expression is reasonable. A mathematical expression for such an impulse function is the Dirac delta function (1), denoted as $\delta(r)$. This function characterizes the initial distribution of spores at $t=0$, that is, it has an area of 1 at $r=0$ and an area of 0 at all other values of $r$ at the start of the rain event.

The entire experimental area (including the point source of spores) is then exposed to rain. It was found that spores at the source decrease exponentially in number $(11,21)$. This can be explained from the physical mechanism with which spores are dispersed. When it starts raining, spores are incorporated in the formed splash droplets and are redistributed around the source in ballistic flight trajectories (8). The number of spores that are splashed away is proportional to the number present at a given time, resulting in an exponential decline. This information can be translated in a second model term that represents the declining number of spores at the source once it starts raining. The Dirac delta function should then be multiplied with the number of spores at the start of the rain, denoted by $N(0, r)$, to get the actual spore numbers. If the number of spores at the source, $N(t, 0)$, decreases proportional to the number present, spores have a certain probability per time unit of being splashed, denoted here by $\lambda \mathrm{min}^{-1}$. The exponentially decreasing spore numbers at $r=0$ can then be described as

$$
N(t, r)=e^{-\lambda t} \delta(r) \cdot N(0, r)
$$

During its first flight from the source, a spore has a probability of landing at a place where it cannot be splashed again. This occurs when a spore lands, for example, in the straw just below the surface. This mechanism explains why fruit disease incidence is lower when straw instead of soil is used as a ground cover (10).

If a spore lands at a place that is not in direct contact with impacting raindrops, it is out of the process for the rest of the rain episode. Spores have a probability of splashing out of the process each time they are impacted by a water drop. Therefore, an expression for the probability of staying in the process per splash should be incorporated in the model, denoted by $\varepsilon$ (unitless). The probability of being removed per splash is then $1-\varepsilon$.

Now, consider the distance a spore can travel when it is splashed away once from the source, given that it stays in the process. Yang et al. (21) performed an experiment in which a fruit was hit by a raindrop (of a range of diameters and impact velocities), and travel distances of the splashing water droplets were measured. A frequency distribution of droplet travel distances could be determined (Fig. 7 in literature citation 21). Since spores are dispersed in these splash droplets, this experiment gives a good representation of spore travel distances from a single drop impaction.

The frequency distribution of droplet travel distances could be approximated by a normal distribution. Any other distributions could be used with tail probabilities smoothly diminishing to zero that would account for skewness of the distribution, such as a double-exponential distribution (16). However, the normal distribution is reasonably robust to some nonsymmetry of the actual distribution. As droplets are dispersed equally around the source, we need a normal distribution in two dimensions to represent droplet travel distances.

Let $D(x, y)$ be the probability density function of a spore traveling to position $(x, y)$ from position $(0,0)$ during one splash. If, for example, $x_{1}$ and $y_{1}$ are normally distributed, both with expectation 0 , and traveling in $x$ and $y$ directions occur uncorrelated, then the spatial density of spores after one splash can be specified as

$$
D\left(x_{1}, y_{1}\right)^{* 1}=\frac{1}{2 \pi \sigma^{2}} e^{\frac{-\left(x_{1}^{2}+y_{1}^{2}\right)}{2 \sigma^{2}}}
$$

in which $\sigma^{2}$ is the variance for the travel distances $x$ and $y$ (13). A spore will continue splashing during the rain. Assume that each time a spore is splashed from any point on the surface it has the same probability density function for travel distances and that during a rain episode spores splash $i$ times. The equation for the spatial spread after being splashed $i$ times, $D(x, y)^{* i}$, can then be derived using the above-discussed method for $i=1$. Using the normal distribution for $D(x, y)(13)$, it follows that

$$
D(x, y)^{*_{i}}=\frac{1}{2 \pi i \sigma^{2}} e^{\frac{-\left(x^{2}+y^{2}\right)}{2 i \sigma^{2}}}
$$

Because the resulting probability distribution is a bivariate normal distribution with $\rho=0$, and so rotationally symmetrical again, the probability is a function of distance $r=\sqrt{x^{2}+y^{2}}$ only, and we can write

$$
D(r)^{*_{i}}=\frac{1}{2 \pi i \sigma^{2}} e^{\frac{-r^{2}}{2 i \sigma^{2}}}
$$

We now have an expression for the decreasing number of spores at the source (equation 1) and an expression for the spatial movement of spores in the field once they have splashed $i$ times (equation 4). The final step here is to determine the probability of being splashed $i$ times.

Some spores are splashed more times than others in a rain episode. Therefore, a probability distribution is incorporated for the number of splashes, $i$ per spore within time $t$, in which the discrete stochastic process for $i=0,1,2, \ldots, \infty$. We assume that spores splash independently and, therefore, the number of splashes for a spore in time $t$ is Poisson distributed. Given that the probability of being splashed per time unit is denoted by $\lambda$, the mean number of splashes during time $t$ equals $\lambda t$. The resulting Poisson probability is

$$
P(i)=\frac{(\lambda t)^{i} e^{-\lambda t}}{i !}
$$

In Pielaat and van den Bosch (16), a partial differential equation was developed to describe the process of splash dispersal. Solving this model, a Poisson distribution represents the probability of a spore being splashed $i$ times at some time during the rain event.

Because each time a spore is splashed it has a probability, $\varepsilon$, of staying in the system, we have to multiply equation 5 by $\varepsilon^{i} \cdot N(0, r)$ to determine the number of spores still in the process and splashed $i$ times. Multiplying equation 5 times $\varepsilon^{i} \cdot N(0, r)$ times equation 4 gives the number of spores found at distance $r$ from the source once they are splashed $i$ times.

Finally, in a rain episode, different spores splash different number of times, all having a different contribution to the number of spores at a certain distance from the source. Therefore, we make a summation over all possible times a spore can be splashed ( $i=1$ to $\infty$ ) to attain the actual spatial spread of spores in the field at any time during a rain event.

This leads to the resulting equation for the number of spores at any arbitrary point on $r$ at time $t$ during the rain:

$$
N(t, r)=\left[e^{-\lambda t} \delta(r)+\sum_{i=1}^{\infty} \frac{(\lambda t)^{i} e^{-\lambda t}}{i !} \varepsilon^{i} \frac{1}{2 \pi i \sigma^{2}} e^{\frac{-r^{2}}{2 i \sigma^{2}}}\right] \cdot N(0, r)
$$

when the model is specified with a normal distribution for $D(r)^{*_{i}}$. Although equation 6 shows an infinite series $\sum_{i=1}^{\infty}$, the individual terms decline relatively soon to 0 . For calculations, we added new terms until the contribution with respect to the previous summation differed by less than $0.001 \%$. This was achieved with an upper summation limit of $i=99$. Dividing both sides of equation 6 by $N(0, r)$ produces the probability of a spore traveling distance $r$ in time $t, P(t, r)(P[t, r]=N[t, r] / N[0, r])$.

A mathematical derivation of this model is described in Pielaat and van den Bosch (16) based on a general solution of a partial differential equation for $P(t, r)$ and an unspecified $D(r)^{* i}$. 
Number of spores during a rain episode. To describe the total number of spores present at all distances surrounding the source, an equation can be derived from equation 6 . Since now we are discussing the change in the number of spores over time, only a time (but no distance) component is needed to describe what happens during a rain episode. Following the model (equation 6), the initial number of spores at the point source declines proportional to the number present. That is, if $N_{1}(t)$ represents the number of spores at the source at time $t$, then

$$
\frac{d N_{1}(t)}{d t}=-\lambda N_{1}(t)
$$

with initial condition $N_{1}(0)=N(0, r)$.

The number of spores away from the source, $N_{2}(t)$, will increase proportional to the number at the source. However, in their first splash from the source, spores already have a nonzero probability of removal from the process $(1-\varepsilon)$. Therefore, the number of spores that reach the field per unit of time is proportional to the number of spores that were splashed from the source multiplied by their probability of remaining in the process during the first splash. Once in the field, spores have a probability per splash of disappearing from the process into the ground (or, in general, out of the system). So, simultaneously with an increase, the number of spores in the field will decrease with a factor, $\lambda(1-\varepsilon)$, proportional to the number present. The equation for $N_{2}(t)$ can then be written as

$$
\frac{d N_{2}(t)}{d t}=\lambda \varepsilon N_{1}(t)-\lambda(1-\varepsilon) N_{2}(t)
$$

with initial condition $N_{2}(0)=0$.

The number of spores that are removed from the process, $N_{3}(t)$, equals the second term in equation 8 and spores directly splashed out of the process from the source, namely,

$$
\frac{d N_{3}(t)}{d t}=\lambda(1-\varepsilon) N_{2}(t)+\lambda(1-\varepsilon) N_{1}(t)
$$

with initial condition $N_{3}(0)=0$.

Solving the equation for $N_{2}(t)$ leads to

$$
N_{2}(t)=-N(0, r)\left[e^{-\lambda t}-e^{-\lambda(1-\varepsilon) t}\right]
$$

This equation shows that the number of spores surrounding the source increases from the start of the rain up to $t^{*}=-\ln (1-\varepsilon) / \lambda \varepsilon$, and then the number decreases again.

To check the correctness of equation 10, it is derived directly from the full model (equation 6) for spore dispersal. Equation 6 shows that during the rain the initial number of spores at the source, $N(0, r)$, declines according to $N(0, r) \cdot e^{-\lambda t}$. Once a spore has left the initial source, it is displaced in the field as

$$
N(t, r)=N(0, r) \sum_{i=1}^{\infty} \frac{(\lambda t)^{i} e^{-\lambda t}}{i !} \varepsilon^{i} D(r)^{*_{i}}
$$

This equation shows the number of spores that traveled a particular distance at some time in a rain episode; whereas now we would like to know the total number of spores over the whole surface surrounding the source in time. To determine the total, sum the number of spores at the different distances from the source. For continuous space, this is done by integrating over all possible places a spore can be at a particular time; therefore,

$$
N(t)=N(0, r) \sum_{i=1}^{\infty} \frac{(\lambda t)^{i} e^{-\lambda t}}{i !} \varepsilon^{i} \int_{0}^{\infty} D(r)^{*_{i}} d r
$$

Since the sum, or integration, of the probability $D(r)^{*_{i}}$ for all possible places is 1 by definition, the solution of equation 12 is

$$
N(t)=N(0, r) e^{-\lambda t} \sum_{i=1}^{\infty} \frac{(\varepsilon \lambda t)^{i}}{i !} \cdot 1
$$

For the following manipulation, it is useful to sum from $i=0$ rather than $i=1$. Because $(\varepsilon \lambda t)^{0} / 0 !=1$, the lower limit on the summation in equation 13 can be changed to 0 and then 1 can be subtracted to give an equivalent expression:

$$
N(t)=N(0, r) e^{-\lambda t} \sum_{i=0}^{\infty} \frac{(\varepsilon \lambda t)^{i}}{i !}-1
$$

The term $\sum_{i=1}^{\infty}(\varepsilon \lambda t)^{i} / i$ ! is the Taylor series expansion of $e^{\varepsilon \lambda t}$. Substituting the exponential expression for the infinite sum results in

$$
N(t)=N(0, r) e^{-\lambda t}\left(e^{\varepsilon \lambda t}-1\right)
$$

which is equal to equation 10 for $N_{2}(t)$.

Measures of distance displacement of spores during a rain. Determining the distances spores travel has been a goal of experimental work using a rain simulator $(3,11,17,22)$. Resulting data sets for the number of spores deposited per time unit at various distances can be used to calculate measures of displacement of spores during rains. First, the total number of spores entering a contour around the source per time unit after some period of rain can be calculated. For that, the number of spores found at each single sampling distance is multiplied by $2 \pi r$, the circumference of a circle. The most obvious summary measure of distance is the mean (or expected) displacement of spores per time during the rain. That is, the mean is determined by multiplying the sampling distances by the accompanying number of spores found for each contour at some time, summing up the resulting numbers, and dividing by the original number of spores at the start of the rain. But, because the initial number of spores at the source is not exactly known for these experiments, only an expected displacement of spores multiplied by the initial number $N(0, r)$ can be calculated from the data: that is,

$$
E[r(t)] N(0, r)=\sum r N(t, r) 2 \pi r
$$

in which, $E[r(t)]=$ the mean distance spores travel from the source, and $N(t, r) 2 \pi r=$ the total number of spores found at a contour with radius $r$ during some time interval in the rain.

In terms of model equation 6 , the expected value for the displacement of spores around the source during a rain can be specified following Doucet and Sloep (1) as

$$
E[r(t)] N(0, r)=\int_{o}^{\infty} r N(t, r) 2 \pi r d r
$$

That is, instead of summing up discrete distances (equation 16), we integrate over all possible locations of the continuous distance variable $r$. Using equation 6 for $N(t, r)$ in equation 17, we find

$$
E[r(t)] N(0, r)=e^{-\lambda t} \frac{1}{2 \sqrt{2 \pi \sigma^{2}}} \sum_{i=1}^{\infty} \frac{(\varepsilon \lambda t)^{i}}{i !} \sqrt{i} N(0, r)
$$

Equation 18, with the parameter values estimated (described in Results) or assumed, can be related to experimental data on spore deposition using calculated $E[r(t)]$ from equation 16 . A different 
expression would result for equation 18 if an other $D(r)^{*_{i}}$ function was used in equation 6 .

For many continuous processes in space, it is easier to derive the mean-squared displacement (15), $E\left(r^{2}\right)$ :

$$
E\left[r^{2}(t)\right] N(0, r)=\sum r^{2} N(t, r) 2 \pi r
$$

The equation for the model of $N(t, r)$ (equation 6) then changes to

$$
E\left[r^{2}(t)\right] N(0, r)=\int_{0}^{\infty} r^{2} N(t, r) 2 \pi r d r
$$

which leads to

$$
E\left[r^{2}(t)\right] N(0, r)=2 \varepsilon \lambda \sigma^{2} t e^{-\lambda(1-\varepsilon) t} N(0, r)
$$

Equation 21 specifies the mean-squared displacement of spores in a rain episode times the original number of spores at the source. Spores will reach their maximum squared distance at $t^{*}=1 / \lambda(1-\varepsilon)$. A striking result is that the mean-squared displacement of spores, $2 \varepsilon \lambda \sigma^{2} t e^{-\lambda(1-\varepsilon) t}$, is independent of the complicated spore travel dis-

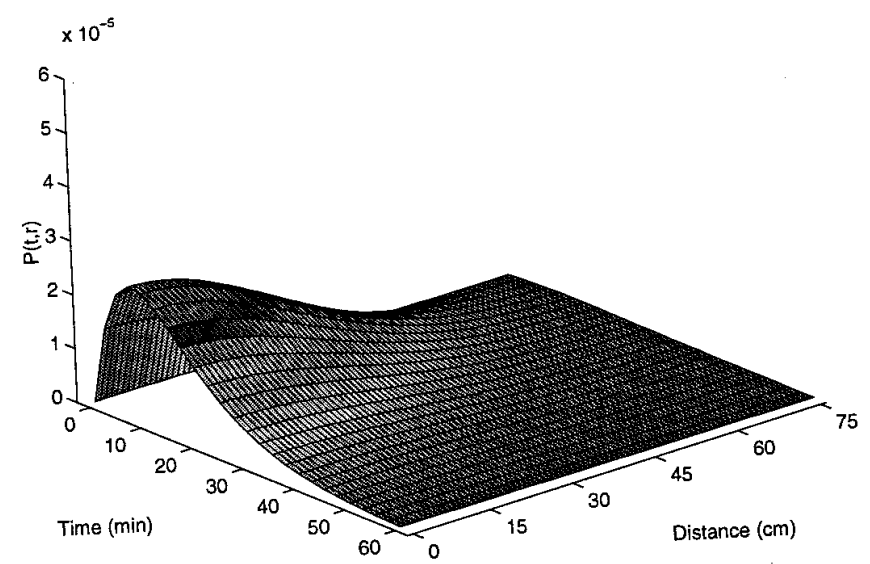

Fig. 1. Probability of a spore traveling distance $r(\mathrm{~cm})$ from a point source of inoculum over time $t$ (min) during a rain event, $P(t, r)$, with $P(t, r)=N(t, r) /$ $N(0, r)$, and $N(0, r)$ being the number of spores at the source (based on equation 6). The probability of being splashed per unit of time, $\lambda$, is $0.13 \mathrm{~min}^{-1}$; the probability of staying in the process per splash event, $\varepsilon$, is 0.25 ; and the standard deviation for $D(r)^{* i}$ (the flight distribution of spores for individual splash events), $\sigma$, is $25 \mathrm{~cm}$.

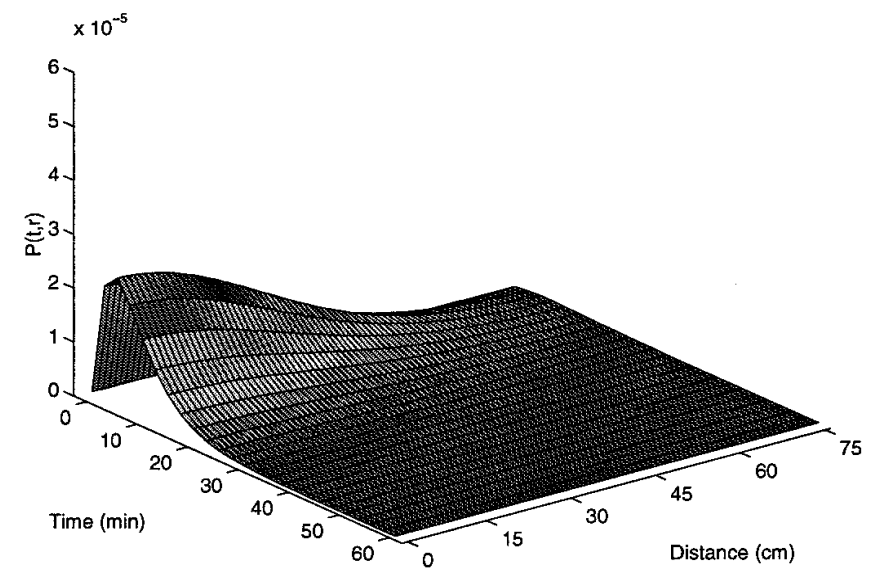

Fig. 2. Probability of a spore traveling distance $r(\mathrm{~cm})$ from a point source of inoculum over time $t$ (min) during a rain event, $P(t, r)$, with $P(t, r)=N(t, r) /$ $N(0, r)$, and $N(0, r)$ being the number of spores at the source (based on equation 6). The probability of being splashed per unit of time, $\lambda$, is $0.25 \mathrm{~min}^{-1}$; the probability of staying in the process per splash event, $\varepsilon$, is 0.25 ; and the standard deviation for $D(r)^{*_{i}}$ (the flight distribution of spores for individual splash events), $\sigma$, is $25 \mathrm{~cm}$ tribution $D^{* i}$ and requires no infinite summation. In fact, equation 21 is valid for all functions. Therefore, it will in many cases be easier to derive and use this quantity than the mean displacement (equation 18), which does depend on $D^{*_{i}}$. Again, equation 21 can be related to experimental data using calculated $E\left[r^{2}(t)\right]$ from equation 19 .

\section{PARAMETER ESTIMATION}

The full model for splash dispersal, equation 6 , in principle could be used to estimate parameters. However, the infinite summation, even approximated by a series from 1 to 99 (or less), is difficult to use in fitting the equation to $N(t, r)$ data. Initial efforts to directly use equation 6 on the ground cover (22) and rain intensity (12) data sets resulted in highly correlated and unreliable parameter estimates. Thus, equations for $N(t)$ and $E\left[r^{2}(t)\right]$, equations 15 and 21, respectively, were used simultaneously to estimate parameters. To use equations 15 and 21 , the observed $N(t, r)$ data were adjusted to obtain $N(t)$ and $E\left[r^{2}(t)\right]$, as described below.

The full model or the pair of models contains four parameters, $N(0, r), \lambda, \varepsilon$, and $\sigma$. The number of spores at the point source $(N[0, r])$

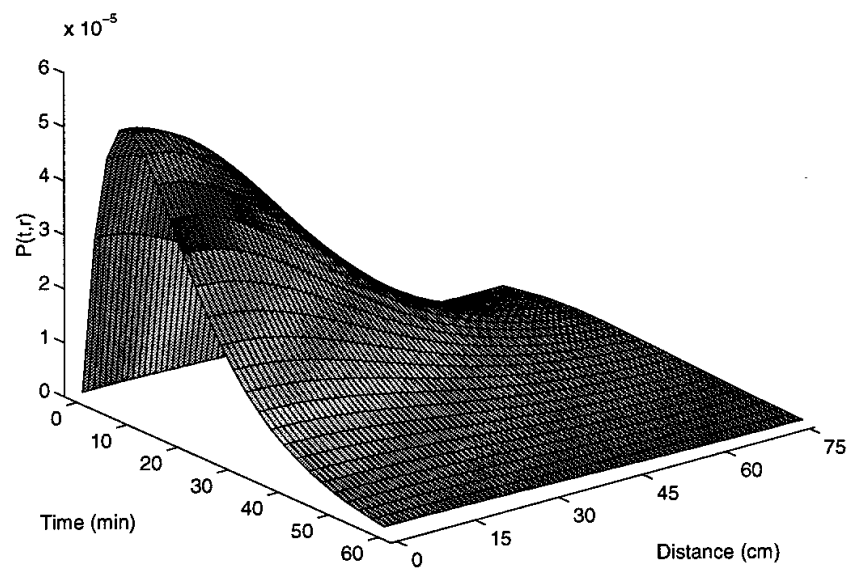

Fig. 3. Probability of a spore traveling distance $r(\mathrm{~cm})$ from a point source of inoculum over time $t$ (min) during a rain event, $P(t, r)$, with $P(t, r)=N(t, r) /$ $N(0, r)$, and $N(0, r)$ being the number of spores at the source (based on equation 6). The probability of being splashed per unit of time, $\lambda$, is $0.13 \mathrm{~min}^{-1}$; the probability of staying in the process per splash event, $\varepsilon$, is 0.50 ; and the standard deviation for $D(r)^{* i}$ (the flight distribution of spores for individual splash events), $\sigma$, is $25 \mathrm{~cm}$.

TABLE 1. Estimated parameters of equations 15 and 21 for splash dispersal of spores with seven rain intensities ${ }^{\mathrm{a}}$

\begin{tabular}{lcccccc}
\hline $\begin{array}{l}\text { Rain } \\
\text { intensity } \\
\left(\mathrm{mm} \mathrm{h}^{-1}\right)\end{array}$ & \multicolumn{3}{c}{ Estimated parameters } & & \multicolumn{2}{c}{ Root MSE $^{\mathrm{b}}$} \\
\cline { 2 - 4 } \cline { 6 - 7 } 2 & $\lambda\left(\mathrm{min}^{-1}\right)$ & $\varepsilon\left(\mathrm{splash}^{-1}\right)$ & $\sigma(\mathrm{cm})$ & & $N(t)$ & $r^{2}(t)$ \\
\hline \multirow{2}{*}{$4^{\mathrm{d}}$} & 0.023 & 0.0002 & 23 & & 2.5 & 1.3 \\
& $(0.010)^{\mathrm{c}}$ & $(0.0004)$ & $(5.8)$ & & \\
7 & 0.002 & 0.033 & 20 & 21 & 21 \\
& $(0.031)$ & $(4.1)$ & $(5.2)$ & & \\
& 0.034 & 0.046 & 20 & 54 & 49 \\
11 & $(0.010)$ & $(0.005)$ & $(1.0)$ & & \\
& 0.026 & 0.130 & 15 & & \\
& $(0.007)$ & $(0.012)$ & $(0.2)$ & & 48 \\
15 & 0.075 & 0.210 & 26 & 2,448 & 756 \\
30 & $(0.013)$ & $(0.025)$ & $(2.2)$ & & \\
& 0.130 & 0.460 & 20 & 3,600 & 982 \\
60 & $(0.015)$ & $(0.031)$ & $(1.3)$ & & \\
& 0.116 & 0.480 & 18 & 4,166 & 521 \\
& $(0.014)$ & $(0.033)$ & $(1.4)$ & & \\
\hline
\end{tabular}

${ }^{a}$ Data of Madden et al. (12). For equations, it was assumed that $N(0, r)=10^{5}$.

${ }^{\mathrm{b}}$ Root mean square error of the observed values around the predicted curves.

c Standard error of estimated parameter in parentheses.

${ }^{\mathrm{d}}$ Model-fitting procedure did not converge. 
was controlled in the experiments described here and was considered to be fixed for all treatments (ground covers or intensities) in an experiment $(12,22)$. Here, we use $N(0, r)=10^{5}$ for the rain intensity study and $N(0, r)=10^{6}$ for the ground cover experiment. The other three parameters were estimated for each treatment using nonlinear least squares regression.

Data adaptations. To calculate the total number of spores in the process at some time during a rain episode, $N(t)$, using equation 15 , the total number of colonies from 0 to the largest radius should be counted. However, only the number of spores per square centimeter per minute at particular distances were determined (12, 22). We assumed that the counted number of spores per square centimeter at some distance is constant at all locations within an annulus around the source. For instance, if spore numbers $N(t, r)$ were measured at 20,40,60, and $80 \mathrm{~cm}$ from the source, then the total numbers within a radius $(r)$ of $20 \mathrm{~cm}$ from the source is estimated as $N(t, 20) \cdot \pi \cdot(20+10)^{2}$. Subsequently, the total number between 20 and $40 \mathrm{~cm}$ from the source is estimated as $N(t, 40) \cdot \pi$. $(40+10)^{2}-N(t, 40) \cdot \pi \cdot(40-10)^{2}$, and so on. Adding up the results gives the total number of colonies within a radius of $80 \mathrm{~cm}$ from the source at some time during the rain.

For each consecutive time in the rain, the mean displacement or mean-squared displacement of spores multiplied by the in-
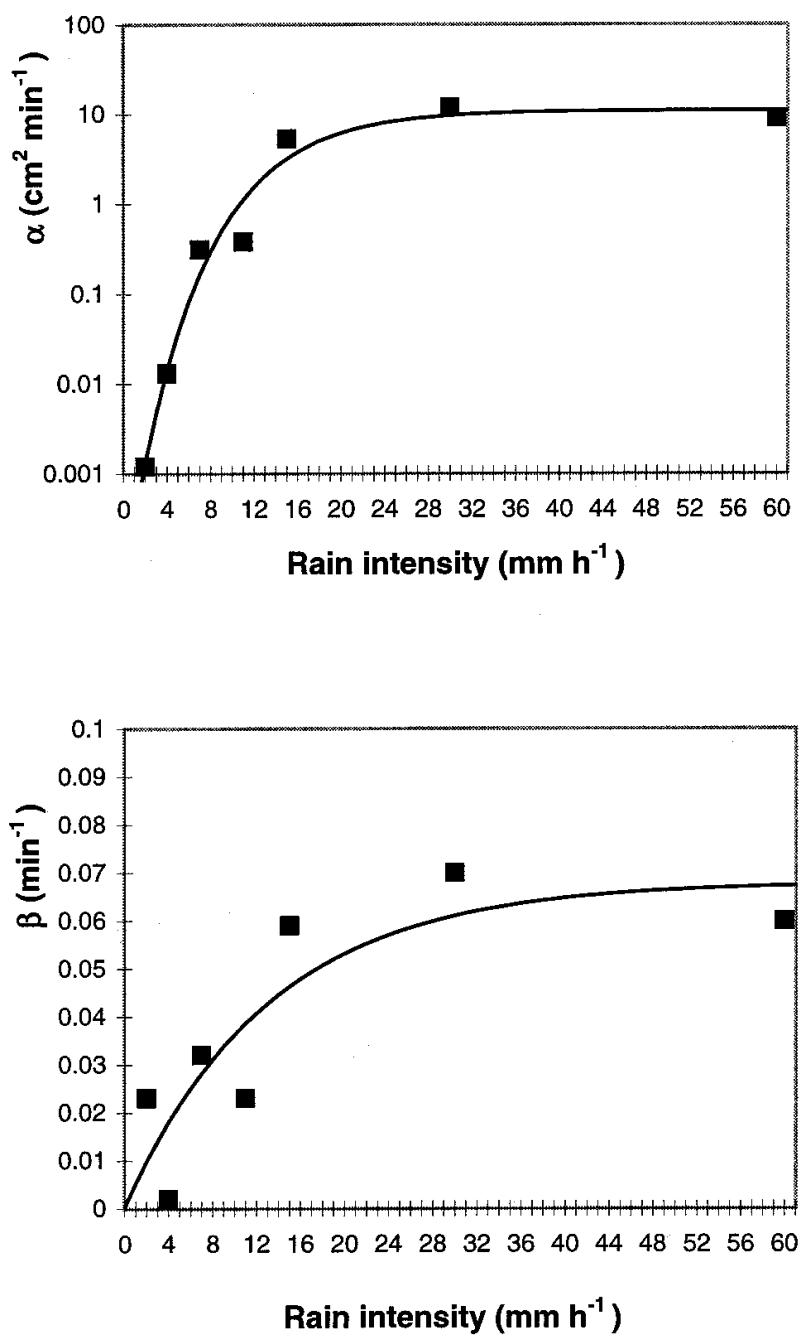

Fig. 4. Estimated dispersal coefficient $\left(\alpha=\varepsilon \lambda \sigma^{2} / 2\right)$ and the rate of spore loss $(\beta=\lambda[1-\varepsilon])$ for increasing rain intensities $\left(I ; \mathrm{mm} \mathrm{h}^{-1}\right)$. Values for $\alpha$, based on estimated parameters in Table 1, could be fitted by a limited exponential growth model of the form $\ln (\alpha)=a-b e^{-c I}$, in which $a=2.39$ (standard error [SE] $=$ $0.51), b=12.30(\mathrm{SE}=1.24)$, and $c=0.15(\mathrm{SE}=0.03)$. For $\beta$, the model $\beta=$ $a-b e^{-c I}$ was used based on estimated parameters in Table 1, in which $a=$ $0.068(\mathrm{SE}=0.016), b=0.068(\mathrm{SE}=0.020)$, and $c=0.076(\mathrm{SE}=0.062)$. itial number can, in principle, be calculated from the data according to equation 16 or 19 . However, as discussed in the above paragraph, only data at specified locations were obtained. Thus, it was assumed that $N(t, r)$ was constant from $r-\Delta r$ to $r+\Delta r$ (with $\Delta r=10 \mathrm{~cm}$ here). That is, for $r=20$, the formula within the summation of equation 16 becomes $r[N(t, 30)] 2 \pi r$; and for $r=40$, $r[N(t, 50)-N(t, 30)] 2 \pi r$.

Statistical analysis. Equations 15 and 21 were simultaneously fitted to the observed data for $N(t)$ and $E\left[r^{2}(t)\right]$, respectively, using nonlinear least squares regression (18). The Gauss-Newton method for minimization of the generalized sum or squares of the residuals (across the two equations) was used in conjunction with the "seemingly unrelated regression" (SUR) parameter estimation method. Calculations were performed with the MODEL procedure of SAS/ ETS (Statistical Analysis System 6.12; SAS Institute, Cary, NC). MODEL determines the analytical partial derivatives of the models with respect to the parameters that are needed in the Gauss-Newton procedure. This procedure can be used for systems of nonlinear equations in which one or more of the parameters are shared by two or more equations. It was assumed that the errors (unexplained variation) for each equation (estimated by the residuals) were identically and independently distributed with zero means and a positive definite covariance matrix. The SUR method allows for the nonzero correlation of the residuals across the equations in determining parameters and their estimated (asymptotic) standard errors.

For the rain intensity study (12), certain functions of the estimated parameters were related to intensity $\left(I ; \mathrm{mm} \mathrm{h}^{-1}\right)$ using a nonlinear empirical model. The model used was either $\ln (y)=\mathrm{a}-b e^{-c I}$ or $y=$ $a-b e^{-c I}$, in which $a, b$, and $c$ are parameters, and $y$ is some combination of the model parameters (e.g., $\lambda[1-\varepsilon]$ ).

\section{RESULTS}

Model simulation. To give a general insight into the model, some simulation results are shown first. After the start of a rain, spores gradually move into the area surrounding the point source. Figure 1 shows a model simulation for $P(t, r)(=N[t, r] / N[0, r])$ with a set of reasonable parameter values (as shown below). Here, $P(t, r)$ increases at least up to approximately $10 \mathrm{~min}$ at all distances from the source. Beyond this time, $P(t, r)$ decreases. This decreasing probability is primarily due to the depletion of spores at the inoculum source and the removal of spores from the system. Figure 2 shows a model simulation in which $\lambda$ is set to a larger value. When $\lambda$ increases, it takes spores less time to be spread to the area surrounding the source, and the probability of being splashed to larger distances in relatively little time increases compared with

TABLE 2. Estimated parameters of equations 15 and 21 for splash dispersal of spores with three ground covers at two rain intensities ${ }^{\mathrm{a}}$

\begin{tabular}{|c|c|c|c|c|c|c|}
\hline \multirow{2}{*}{$\begin{array}{l}\text { Ground } \\
\text { cover }\end{array}$} & \multirow{2}{*}{$\begin{array}{c}\text { Rain } \\
\text { intensity } \\
\left(\mathrm{mm} \mathrm{h}^{-1}\right)\end{array}$} & \multicolumn{3}{|c|}{ Estimated parameters } & \multicolumn{2}{|c|}{ Root MSE ${ }^{b}$} \\
\hline & & $\lambda\left(\mathrm{min}^{-1}\right)$ & $\varepsilon\left(\right.$ splash $\left.^{-1}\right)$ & $\sigma(\mathrm{cm})$ & $N(t)$ & $r^{2}(t)$ \\
\hline Plastic & 15 & $\begin{array}{l}0.12 \\
(0.008)^{\mathrm{c}}\end{array}$ & $\begin{array}{c}0.05 \\
(0.003)\end{array}$ & $\begin{array}{l}32 \\
(2.2)\end{array}$ & 1,826 & 1,159 \\
\hline Soil & & $\begin{array}{c}0.09 \\
(0.02)\end{array}$ & $\begin{array}{l}0.05 \\
(0.007)\end{array}$ & $\begin{array}{l}36 \\
(1.6)\end{array}$ & 5,335 & 215 \\
\hline Straw & & $\begin{array}{c}0.12 \\
(0.022)\end{array}$ & $\begin{array}{c}0.03 \\
(0.006)\end{array}$ & $\begin{array}{l}32 \\
(2.2)\end{array}$ & 3,873 & 969 \\
\hline Plastic & 30 & $\begin{array}{l}0.20 \\
(0.012)\end{array}$ & $\begin{array}{c}0.19 \\
(0.012)\end{array}$ & $\begin{array}{l}27 \\
(0.7)\end{array}$ & 6,610 & 1,725 \\
\hline Soil & & $\begin{array}{l}0.13 \\
(0.005)\end{array}$ & $\begin{array}{l}0.10 \\
(0.005)\end{array}$ & $\begin{array}{l}29 \\
(3.0)\end{array}$ & 2,528 & 2,636 \\
\hline Straw & & $\begin{array}{c}0.25 \\
(0.018)\end{array}$ & $\begin{array}{c}0.09 \\
(0.007)\end{array}$ & $\begin{array}{l}20 \\
(1.0)\end{array}$ & 3,060 & 585 \\
\hline
\end{tabular}

${ }^{a}$ Data of Yang et al. (22). For equations, it was assumed that $N(0, r)=10^{6}$.

${ }^{b}$ Root mean square error of the observed values around the predicted curves.

${ }^{c}$ Standard error of estimated parameter in parentheses. 
Figure 1. Setting $\varepsilon$ to a larger value increases $P(t, r)$ in time for all distances (Fig. 3).

Parameter estimates. Table 1 shows the estimates and accompanying (asymptotic) standard errors for $\lambda, \varepsilon$, and $\sigma$ when all three parameters were simultaneously estimated for the rain intensity data of Madden et al. (12).

The nonlinear least squares procedure converged for all rain intensities except $4 \mathrm{~mm} \mathrm{~h}^{-1}$, although parameter estimates were reasonable for this intensity as well. Spore deposition was very low (but nonzero) at the lowest rain intensities (Fig. 2 in literature citation 12), and there probably was insufficient change in $N(t, r)$ with increasing $t$ and $r$ (or change in $N[t]$ with increasing $t$ ) for the least squares procedure to converge at $4 \mathrm{~mm} \mathrm{~h}^{-1}$. Standard errors were very small except for the lack of convergence case. Correlations of the estimated parameters were all under 0.75 , and three quarters were less than 0.5 .

There were clear trends in the parameter estimates with increasing intensity. Except for $11 \mathrm{~mm} \mathrm{~h}^{-1}$, the estimated probability of being splashed per time unit, $\lambda$, increased with rain intensity up to $30 \mathrm{~mm} \mathrm{~h}^{-1}$. Because the number and size of both impacting drops and splashing droplets increases with increasing rain intensity (12), $\lambda$ was expected to follow this trend. For $60 \mathrm{~mm} \mathrm{~h}^{-1}$, the estimated $\lambda$ was slightly less than for $30 \mathrm{~mm} \mathrm{~h}^{-1}$, but the difference was not significant, suggesting that a maximum $\lambda$ was reached. The increase in water puddles at the highest intensity (L. V. Madden, unpublished data) may dilute the surface density of spores per area, thus decreasing the probability of splash.
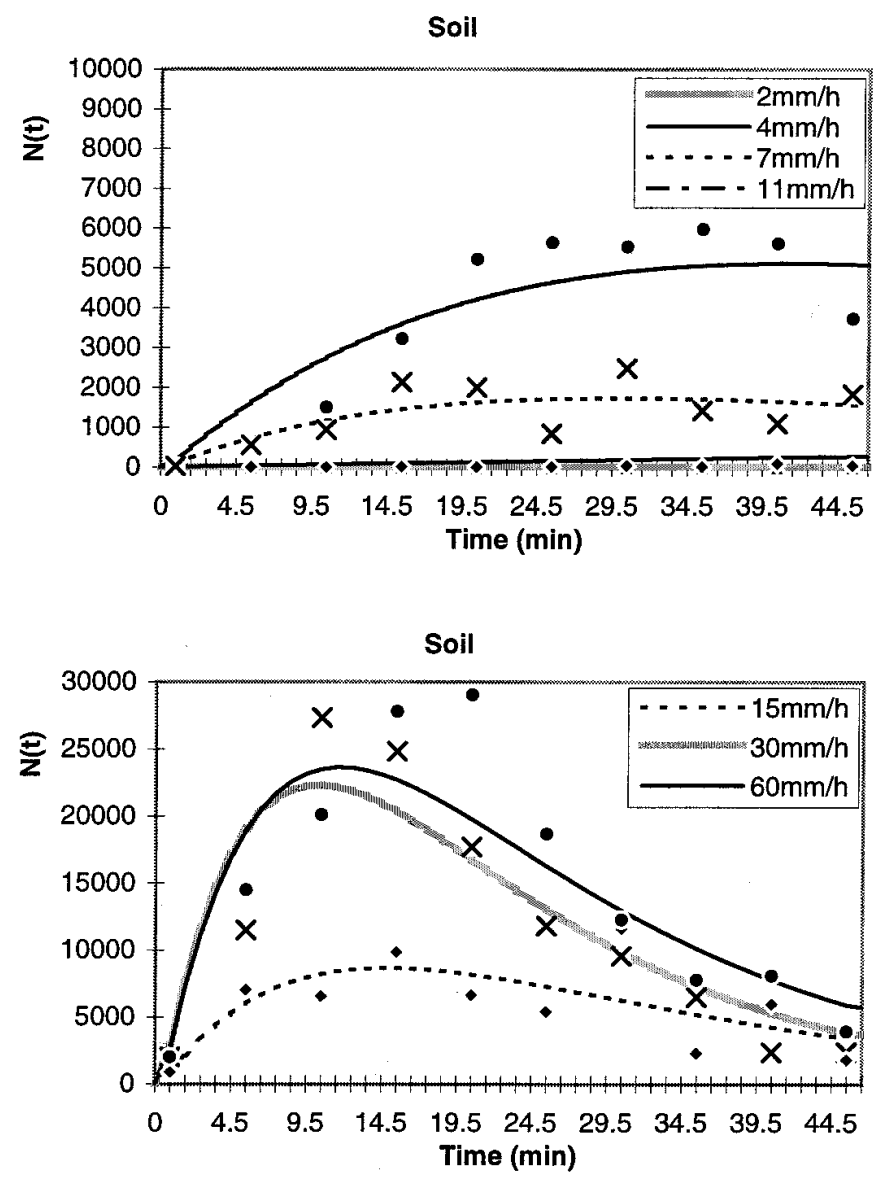

Fig. 5. Change in the total number of spores across a circular area (with a radius of $100 \mathrm{~cm}), N(t)$, during a rain event for seven different intensities using soil as a ground cover. Symbols used for the observed values are triangles for $2 \mathrm{~mm} \mathrm{~h}^{-1}$, diamonds for 4 and $15 \mathrm{~mm} \mathrm{~h}^{-1}$, crosses for 7 and $30 \mathrm{~mm} \mathrm{~h}^{-1}$, and dots for 11 and $60 \mathrm{~mm} \mathrm{~h}^{-1}$. Data are from Madden et al. (12) for the number of spores per square centimeter per minute at various times $(t)$ and distances $(r)$ from the source, $N(t, r)$. Curves are based on equation 15 with parameter estimates in Table 1 , with an assumed source strength $(N[0, r])$ of $10^{5}$ spores.
The estimated probability of staying in the process per splash, $\varepsilon$, also increased with rain intensity. At intensities of $\leq 7 \mathrm{~mm} \mathrm{~h}^{-1}, \varepsilon$ was less than 0.05 , meaning that the probability of being removed per splash $(1-\varepsilon)$ was greater than 0.95 .

The estimated measure of distance a spore splashes, $\sigma$, was invariant to intensity (Table 1 ). That is, $\sigma \approx 20 \mathrm{~cm}$ at all intensities.

In Figure 4, the so-called "diffusion" coefficient $\left(\alpha=\lambda \varepsilon \sigma^{2} / 2\right)$, and the rate of spore loss $(\beta=\lambda[1-\varepsilon])$ (16) are plotted versus rain intensity. There was a general increase in $\alpha$ and $\beta$ with intensity at low intensities, with a leveling off at $\geq 30 \mathrm{~mm} \mathrm{~h}^{-1}$.

Table 2 shows the estimated parameter values and accompanying (asymptotic) standard errors for the ground cover data of Yang et al. (22), when three parameters were simultaneously estimated.

As with the intensity experiment (12) described above, both $\lambda$ and $\varepsilon$ increased when rain intensity increased from 15 to $30 \mathrm{~mm} \mathrm{~h}^{-1}$. Estimated $\sigma$ decreased slightly with increasing intensity; however, the values of $\sigma$ at $30 \mathrm{~mm} \mathrm{~h}^{-1}$ were similar to those determined in the intensity experiment (Table 1). Furthermore, $\lambda$ for soil at 15 and $30 \mathrm{~mm} \mathrm{~h}^{-1}$ with the ground cover experiment (Table 2) were very similar to the estimates for these intensities with the rain intensity experiment. Surprisingly, $\lambda$ was larger for straw than for soil.

For the $30-\mathrm{mm} \mathrm{h}^{-1}$ rain intensity, the probability of staying in the process per splash, $\varepsilon$, was largest when plastic was used as ground cover $(\varepsilon \approx 0.2)$ and smallest when straw was used $(\varepsilon \approx 0.1)$.
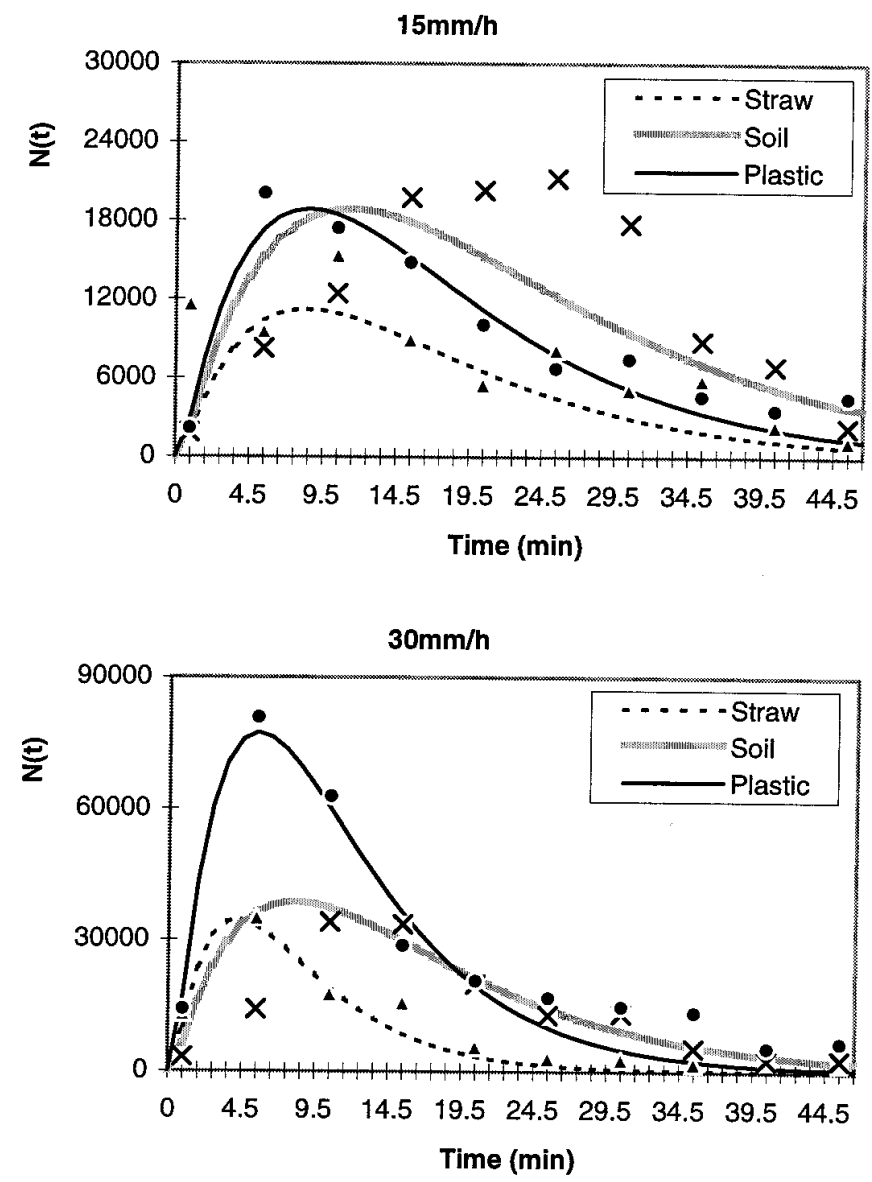

Fig. 6. Change in the total number of spores across a circular area (with a radius of $120 \mathrm{~cm}$ ), $N(t)$, during a rain event for two different intensities using straw, soil, or plastic as a ground cover. Symbols used for the observed values are triangles for straw, crosses for soil, and dots for plastic. Data are from Yang et al. (22) for the number of spores per square centimeter per minute at various times $(t)$ and distances $(r)$ from the source, $N(t, r)$. Curves are based on equation 15 with parameter estimates in Table 2 , with an assumed source strength $(N[0, r])$ of $10^{6}$ spores. 
For $15 \mathrm{~mm} \mathrm{~h}^{-1}$, this trend was somewhat less clear and $\varepsilon$ was only affected by straw (0.05 versus 0.03$)$. However, the lower values overall for $\varepsilon$ at this intensity make it more difficult to quantify differences.

At an intensity of $30 \mathrm{~mm} \mathrm{~h}^{-1}$, the estimated $\sigma$ for plastic and soil $(\sigma \approx 28 \mathrm{~cm})$ was greater than for straw $(\sigma \approx 20)$. At $15 \mathrm{~mm} \mathrm{~h}^{-1}, \sigma$ was not greatly affected by ground cover. From this study, it can be seen that the effect of ground cover on dispersal components is most discernible at high rain intensity.

Number of spores. According to equation 15 and reasonable parameter values, the total number of spores in the field at time $t$, $N(t)$, should initially increase during a rain episode.

This trend can be seen in Figures 5 and 6 when the model is applied to experimental data sets. Figure 5 shows $N(t)$ over time for the data sets with different rain intensities (12), all with the same ground cover. Because $\lambda$ generally increased with intensity (Table 1 ), the maximum number of spores was predicted to be reached after a relatively short period of rain at high rain intensity compared with low intensity (at $t^{*}=-\ln (1-\varepsilon) / \lambda \varepsilon$ ). Also, $N(t)$ overall was predicted to increase with intensities because of the term in equation 15, at least until spore removal (reflected by $\varepsilon$ ) dominates over the number of spores leaving the source. Both data and model outcome agree with these general expectations (Fig. 5). Only from 30 to $60 \mathrm{~mm} \mathrm{~h}^{-1}$ did $N(t)$ fail to consistently increase with intensity, probably because $\lambda$ did not

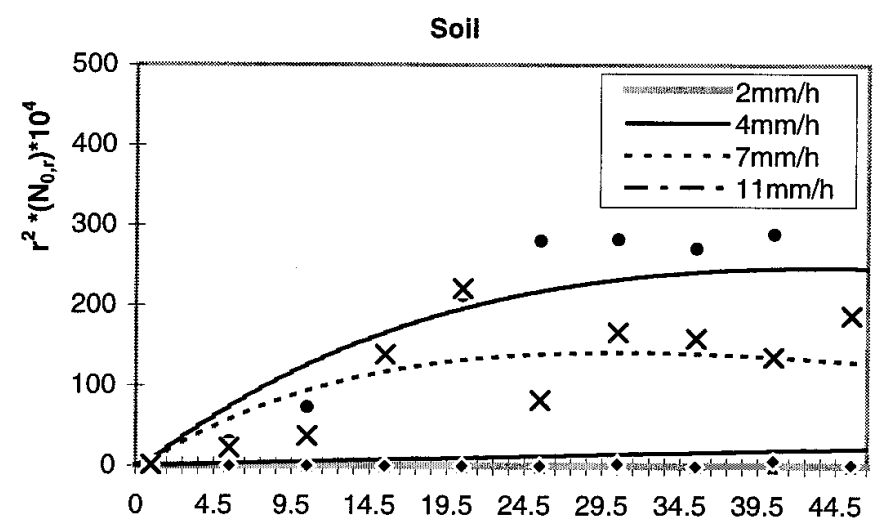

Time $(\min )$

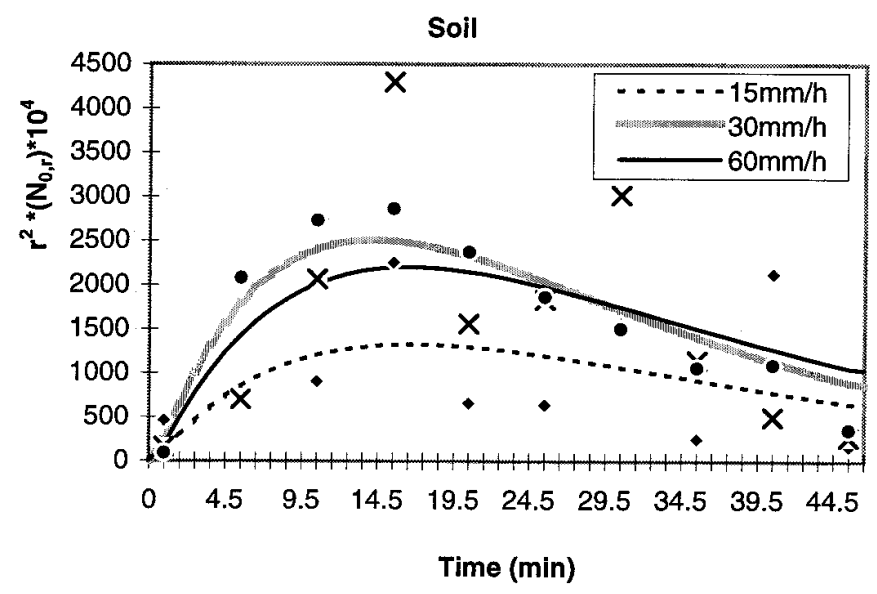

Fig. 7. Mean squared distance spores travel times initial number $(N[0, r])$, $E\left(r^{2}\right) N(0, r)$, during a rain event for seven different intensities using soil as a ground cover. Symbols used for the observed values are triangles for $2 \mathrm{~mm} \mathrm{~h}^{-1}$, diamonds for 4 and $15 \mathrm{~mm} \mathrm{~h}^{-1}$, crosses for 7 and $30 \mathrm{~mm} \mathrm{~h}^{-1}$, and dots for 11 and $60 \mathrm{~mm} \mathrm{~h}^{-1}$. Data are from Madden et al. (12) for the number of spores per square centimeter per minute at various times $(t)$ and distances $(r)$ from the source, $N(t, r)$. Observed $E\left(r^{2}\right) N(0, r)$ was calculated with equation 19. Curves are based on equation 21 with parameter estimates in Table 1, with an assumed source strength $(N[0, r])$ of $10^{5}$ spores. increase. For the low rain intensities $\left(<15 \mathrm{~mm} \mathrm{~h}^{-1}\right)$, the probability of being splashed was small (Table 1), and $N(t)$ was still increasing even after 45 min of rain (Fig. 5).

For the high rain intensities, the maximum number of spores splashed across an area was reached quickly, and $\varepsilon$ then dominates the process.

If plastic is used as a ground cover (Fig. 6), more spores are expected to stay in the process compared with other ground covers, causing a larger $N(t)$ than for soil or straw $(9,22)$.

This was clearly seen for $30 \mathrm{~mm} \mathrm{~h}^{-1}$ and, to a lesser extent, for $15 \mathrm{~mm} \mathrm{~h}^{-1}$ (in which there was only a slight difference between plastic or soil versus straw). These results can be predicted from the model because of the large $\varepsilon$ for plastic compared with the other covers at $30 \mathrm{~mm} \mathrm{~h}^{-1}$ (Table 2). At the lower intensity, $\varepsilon$ for plastic was slightly higher than for straw, but not for soil, although all values were low for $\varepsilon$. At $30 \mathrm{~mm} \mathrm{~h}^{-1}, N(t)$ for soil and straw was similar at low $t$, and then soil had the larger $N(t)$, presumably because of the combined effects of $\varepsilon$ and $\lambda$. At $15 \mathrm{~mm} \mathrm{~h}^{-1}$, straw clearly had the lowest $N(t)$ of the three ground covers, which can be explained by the small, but significant, difference in $\varepsilon$ between straw and plastic.

Measures of displacement. Figures 7 and 8 illustrate data and model predictions for the mean-squared travel distance of spores times $N(0, r)$ for different intensities and ground covers $(22,12)$. In general, $E\left(r^{2}\right)$ increased with most rain intensities, and the time of
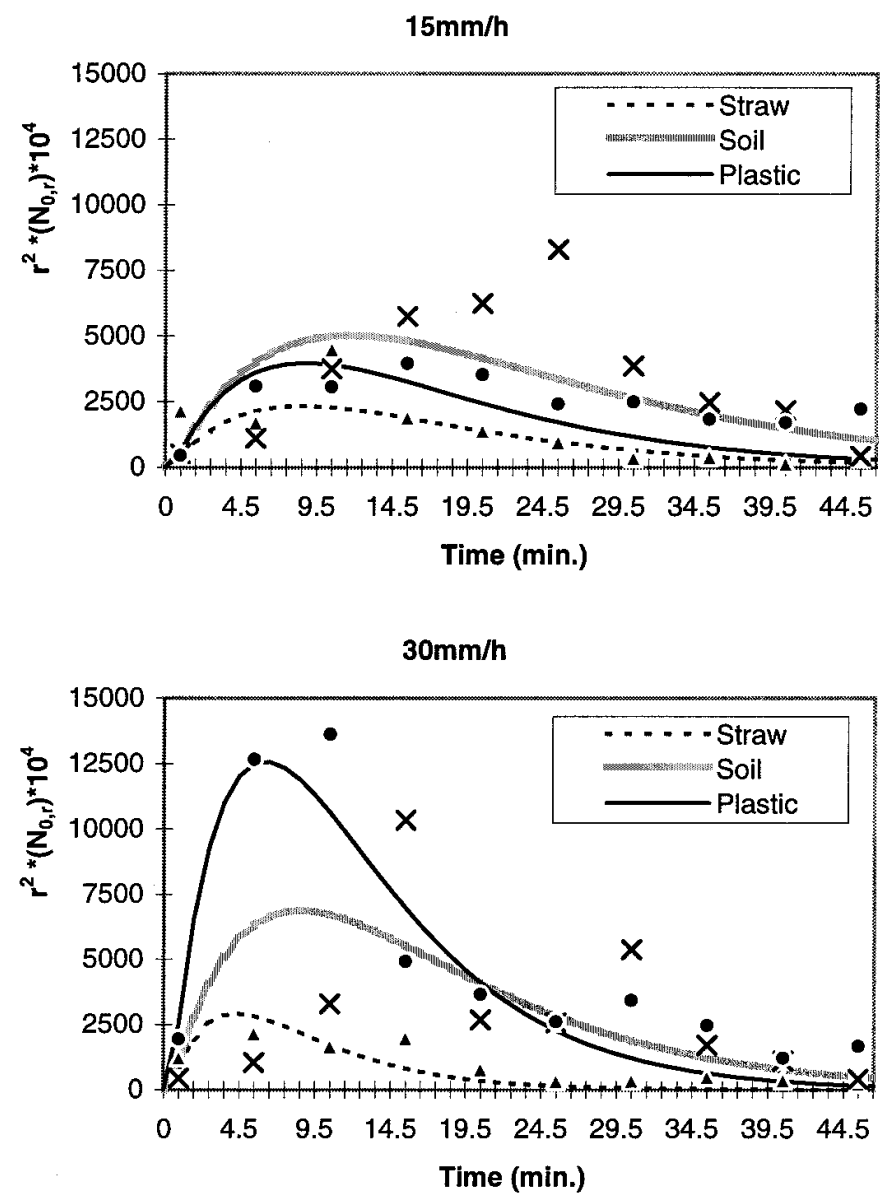

Fig. 8. Mean squared distance spores travel times initial number $(N[0, r])$, $E\left(r^{2}\right) N(0, r)$, during a rain event for two different intensities using straw, soil, and plastic as a ground cover. Symbols used for the observed values are triangles for straw, crosses for soil, and dots for plastic. Data are from Yang et al. (22) for the number of spores per square centimeter per minute at various times $(t)$ and distances $(r)$ from the source, $N(t, r)$. Observed $\mathrm{E}\left(r^{2}\right) N(0, r)$ was calculated with equation 19. Curves are based on equation 21 with parameter estimates in Table 2, with an assumed source strength $(N[0, r])$ of $10^{6}$ spores. 
the maximum $E\left(r^{2}\right)$ was shorter for high intensity rains than low intensity ones. Also, surface topography affected the magnitude of $E\left(r^{2}\right)$, especially at $30 \mathrm{~mm} \mathrm{~h}^{-1}$. Model results using parameter estimates of Tables 1 and 2 agree with the observations. The figures show that, during a rain episode, observed mean-squared displacement first increased and then decreased. Spores being lost from the system, that is, $\varepsilon<1$, causes this result in the model. In fact, if $\varepsilon=1, E\left(r^{2}\right)$ reduces to the linear function $2 \lambda \sigma^{2} t$.

Because $\lambda$ generally increased with intensity (Table 1 ), the distance spores traveled by a certain time was also expected to increase and then decrease again as spores are removed. This can be seen in Figure 7. Maximum values for $E\left(r^{2}\right)$ ranged from about $400 \mathrm{~cm}^{2}\left(\left[E\left(r^{2}\right)\right]^{1 / 2} \approx 20 \mathrm{~cm}\right)$ for a $30-\mathrm{mm} \mathrm{h}^{-1}$ rain down to $<10 \mathrm{~cm}^{2}$ $\left(\left[E\left(r^{2}\right)\right]^{1 / 2}<3 \mathrm{~cm}\right)$ for intensities under $5 \mathrm{~mm} \mathrm{~h}^{-1}$.

Ground cover had a major effect on $E\left(r^{2}\right)$ (Fig. 8). Maximum values for $E\left(r^{2}\right)$ ranged from about $30 \mathrm{~cm}^{2}\left(\left[E\left(r^{2}\right)^{1 / 2} \approx 5 \mathrm{~cm}\right)\right.$ for straw to about $125 \mathrm{~cm}^{2}\left(\left[E\left(r^{2}\right)\right]^{1 / 2} \approx 11 \mathrm{~cm}\right)$ for plastic at $30 \mathrm{~mm} \mathrm{~h}^{-1}$. At the lower rain intensity, $E\left(r^{2}\right)$ was more similar among the ground covers, with some observed values greater for soil than for plastic. In agreement with this observation, estimated parameters were more similar among the ground covers.

\section{DISCUSSION}

A model was proposed here (equation 6) to represent the spatial spread of spores by rain splash from a point source at any time during a rain event over a homogeneous surface. The model was based on (i) a probability per time unit of a spore being splashed, (ii) a probability per splash event of a spore being removed from the dispersal process, and (iii) a probability function for the distance a spore travels during a single splash event. A nonlinear least squares analysis for systems of equations was successfully used to fit the model to the experimental data. Results showed the model was applicable for characterizing splash dispersal under a range of conditions including situations with small and large numbers of dispersed spores.

Although the full model developed here for $N(t, r)$ (equation 6) reproduces the general pattern of spore deposition in relation to time and distance (Fig. 1 compared with Fig. 2 in literature citation 12), the model is fairly complicated, including an infinite summation. However, composite variables were derived that are of direct biological relevance and are represented by relatively simple equations. For instance, integration over distance resulted in a description of the change in the total number of spores in the area surrounding the source in time $(N[t]$; equation 15). This equation shows that the predicted $N(t)$ increases to a maximum (dependent on $\lambda$ and $\varepsilon$ ) and then declines. This is because, in the model, the supply of new spores into the field from the source will predominate over the numbers being splashed out of the process (removed) during the early period of rain. Eventually, depletion of spores at the source will occur (equation 1) and, ultimately, few spores will be added to the total number already present in the field. At this later time, the number of spores being splashed out of the process will predominate over new spores from the source, and the predicted $N(t)$ will decrease. Equation 15 also gives insight in the time at which $N(t)$ reaches a maximum for different conditions. Testing equation 15 with experimental data showed that the model followed the same general trend as the experimental results, although the predicted $N(t)$ did not reach the same maxima as the observed $N(t)$ (Figs. 5 and 6) in some cases. As expected, the maximum number of spores over the area increased with rain intensity (Fig. 5); also, the maximum number was greatly affected by surface topography, with the largest values for plastic (Fig. 6) and the lowest values for the rougher straw.

In addition to a function for $N(t)$, models were derived from equation 6 for the mean $(E[r]$; equation 18$)$ and mean-squared ( $E\left[r^{2}\right]$; equation 21) distances that the population of spores travels in splash droplets from the inoculum source during rain episodes, multiplied by $N(0, r) . E\left(r^{2}\right)$ is used frequently to describe spatial spread in biological systems (15), partly because the mathematical function for this variable is often a relatively simple expression. In fact, $E(r)$ cannot always be derived for spread or dispersal models. $E\left(r^{2}\right)$ emphasizes the population of spores that have traveled a distance somewhat above the mean, that is, $E\left(r^{2}\right)=\operatorname{variance}(r)+$ $[E(r)]^{2}$. Thus, $\left[E\left(r^{2}\right)\right]^{1 / 2}$ is always greater than $E(r)$. Because those spores that travel the larger distances are responsible for disease spread into new areas, $E\left(r^{2}\right)$ (or $\left[E\left(r^{2}\right)\right]^{1 / 2}$ ) gives a good impression of the potential disease spread in a crop. Although the expression for $E(r)$ was very complicated, including the $D^{* i}$ term, the function for $E\left(r^{2}\right)$ was simple (equation 21) and easily interpreted. Specifically, predicted $E\left(r^{2}\right)$ was directly related to the product of $\lambda, \varepsilon$, and $\sigma^{2}$, all of which have direct physical meaning. Early in a rain event, the $E\left(r^{2}\right)$ predicted from the model increases over time with a slope determined by $2 \lambda \varepsilon \sigma^{2}$. However, because of the multiplication of this product with the exponential term (equation 21), $E\left(r^{2}\right)$ reaches a maximum at a time that depends on $\lambda$ and $\varepsilon$ (when $\varepsilon<1$ ). Model results in Figures 7 and 8 can be explained by considering the splash of spores near and far from the source, early and late during a period of rain. Early in a rain event, most spores would be close to the source because splashes are of a short distance (21) and droplets move in all directions. The rare spores at large distances would have arrived by one or a few long-distance splashes. Because at this early stage a spore would be splashed relatively few times, removal from the system does not dominate and mean-squared displacement is small. Over time, as the number of splashes increases, there is a net increase in $E\left(r^{2}\right)$ for a while as some spores move to greater distances, mostly in many separate and short-distance splashes. However, some spores are removed with every splash (when $\varepsilon<1$ ), and the probability of a spore remaining in the system after many splashes is small. Spores that could have reached large distances with sufficient time if $\varepsilon=1$ would be removed, and most spores in the area would be those close to the source that had splashed just a few times. This would correspond to a decrease in $E\left(r^{2}\right)$. The exact time when $E\left(r^{2}\right)$ decreases would depend on all the components of the dispersal process, as summarized by the parameters $\lambda, \varepsilon$, and $\sigma$ (equation 21). Model results were in general agreement with observed data for the rain intensity and ground cover experiments (Figs. 7 and 8), with the magnitude of $E\left(r^{2}\right)$ and time of maximum $E\left(r^{2}\right)$ being dependent on experimental conditions.

In a previous paper, Yang et al. (20) developed a generalized diffusion model for describing spore dispersal by rain splash. This diffusion equation was subsequently used by Madden et al. (12) and Ntahimpera et al. (14) as the standard model for characterizing dispersal with the rain simulator. Pielaat and van den Bosch (16) recently showed that the diffusion model is a special case of equation 6, with combined parameters of our model being analogous to the parameter values $\alpha$ and $\beta$ previously used in the diffusion equation for splash dispersal (Fig. 4). However, the diffusion approximation appears only to be valid in the limit as $\lambda \rightarrow \infty, \varepsilon \rightarrow 1$, and $\sigma \rightarrow 0$ (16). A disadvantage of the diffusion model is that $E\left(r^{2}\right)$ is a monotonically increasing function of time, which is not consistent with the observed results (Figs. 7 and 8) and predictions from equation 6. Thus, the model proposed here is an improvement over the commonly used diffusion model, both in terms of generality and describing observed data.

Factors influencing the splash-dispersal process could be captured by changing one or more of the three parameters of equation 6 . On an individual basis, a consistent trend was found for several estimated parameters in relation to rain intensity or surface roughness. Both the probability of being splashed, $\lambda$, and the probability of staying in the process, $\varepsilon$, increased with rain intensity (Table 1 ). The low rate of splashing $(\lambda)$ for low-intensity rains is consistent with the premise that few spores were removed per unit of time at 
these intensities (because few were splashed), but those that were splashed were mostly removed from the process. The trend between $\varepsilon$ and intensity may reflect the formation and depth of a water layer on the soil. That is, at low intensity, there is relatively little water on the surface (L. V. Madden, unpublished data), and we postulate that most splashed spores may be lost through the soil pores. At high rain intensity, saturation of soil with water is approached and eventually reached. This means puddles are being formed. Under these conditions, we believe spores would be more likely to splash from puddle to puddle and not be removed from the system through pores. Therefore, $\varepsilon$ would increase with rain intensity.

Increasing surface roughness (e.g., plastic versus straw) was characterized by decreasing estimates of $\varepsilon$ and $\sigma$, primarily at high rain intensities (Table 2). This result agrees with the premise that more spores stay in the process when a less permeable ground cover is used (22). Because plastic has a relatively impermeable structure, spores can travel over larger distances (in individual splashes or in total over many splashes) with this surface compared with straw (19). This could be due to larger $\sigma$ or $\varepsilon$ for plastic (Table 2), producing larger mean-squared displacement of spores during a rain for plastic than for straw. As $\sigma$ is directly related in the model development to distances spores splash in individual splash events, it is likely, based on parameter estimates, that spores move over a larger distance when splashed from plastic and soil than when splashed from straw. In this scenario, soil would have an intermediate $E\left(r^{2}\right)$, which was found for $30 \mathrm{~mm} \mathrm{~h}^{-1}$ (Fig. 8). The large difference in $\varepsilon$ between plastic and soil (Table 2) at this high intensity could explain the observed result.

Although we placed no a priori conditions on the parameter estimates, other than a zero lower boundary (and an upper boundary of 1 for $\varepsilon$ ), estimated values were consistent with results from independent studies on spores or water movement. For instance, Madden et al. (12), in independent studies from those used here, determined the rate of spore removal directly from the source fruit (rather than based on spore deposition away from the source), essentially using equation 1 . Rate of removal in this setting is equivalent to the probability per unit of time of being splashed. They found that the estimated rate of removal for a $60-\mathrm{mm} \mathrm{h}^{-1}$ rain was about $0.12 \mathrm{~min}^{-1}$, essentially the same as our result of $\lambda=0.116 \mathrm{~min}^{-1}$ at the same intensity. They also found an increase in the removal rate with increasing intensity. Furthermore, using individual drop impaction data (21) and known properties of drop size distributions for natural rains, Madden et al. (12) predicted that the mean flight distance of the population splash droplets from strawberry fruit (roughly related to $\sigma$ ) would increase only slowly with rain intensity above $10 \mathrm{~mm} \mathrm{~h}^{-1}$ (Fig. 4E in literature citation 12). Thus, with inherent experimental variation, it is not surprising that estimated $\sigma$ was stable with rain intensity in this study (Table 1). In a separate study, Yang and Madden (19) directly assessed the transport of splashed water droplets across three ground covers, without spore dispersal and with minimal resplashing. Assuming an exponential distribution of droplet flights (19), calculated $\sigma$ values of Yang and Madden (Table 4 from literature citation 19) were of the same magnitude as our estimated $\sigma$ values. Moreover, water droplet-based $\sigma$ values decreased as surface roughness increased from plastic to straw (19), as found here for spore movement at $30 \mathrm{~mm} \mathrm{~h}^{-1}$ (Table 2).

Although the full model for $N(t, r)$ (equation 6) was of direct use in describing splash dispersal from a point source under controlled and fairly uniform conditions, this model and those derived from it (N[t]; equation 15 ; and $E\left[r^{2}\right]$; equation 21$)$ may be equally useful in risk assessment under natural conditions. That is, because approximate values can be assigned to $N(0, r), \lambda$, $\varepsilon$, and $\sigma$ based on controlled studies, the magnitude of $N(t)$ and $E\left(r^{2}\right)$ can then be predicted under various field situations. For instance, the risk of disease spread for different recorded rain intensities could be assessed based on assumed parameter values. Of course, calculated
$N(t)$ and $E\left(r^{2}\right)$ would serve more as indices of the magnitude of spore number and distance displacement than as actual predictions with this approach. In subsequent research, we will expand the full model to represent spore movement within and across a plant canopy to more fully describe field conditions under less homogeneous conditions. Other research will focus on the spore transport distribution, $D^{*_{i}}$ (equation 4). Because rainfall consists of a distribution of drop sizes (9), and each drop impact potentially can produce a distribution of splash droplets containing spores, with the numbers dependent on the properties of the raindrops and surface (21), work is needed to more fully characterize the link between rain and spore movement. Incorporating rainfall distribution attributes into $D^{* i}$ should give further insight into splash dispersal and possibly improve the model predictions of $N(t)$ and $E\left(r^{2}\right)$.

\section{ACKNOWLEDGMENTS}

The investigations for project 05-39-181 were supported by the Life Sciences Foundation (SLW), which is subsidized by the Netherlands Organization for Scientific Research (NWO). Additionally, the work of L. V. Madden is supported by the U.S. Department of Agriculture grant 95-37303-1788. We thank M. J. Jeger for helpful discussions on the subject treated in this paper and F. van den Bosch for valuable discussions and critically reading the manuscript. A. Pielaat also thanks the whole plant epidemiology group of the Ohio State University in Wooster, especially L. Wilson, W. Turechek, M. Lipps, J. Shorts, N. Ntahimpera, and B. Ellis for their hospitality and N. Ntahimpera and B. Ellis for showing her how to get soaked from a rain simulator.

\section{LITERATURE CITED}

1. Doucet, P., and Sloep, P. B. 1992. Mathematical Modeling in the Life Sciences. Ellis Horwood Limited, Chichester, England.

2. Fitt, B. D. L., Gregory, P. H., Todd, A. D., McCartney, H. A., and Macdonald, O. C. 1987. Spore dispersal and plant disease gradients; a comparison between two empirical models. J. Phytopathol. 118: 227-242.

3. Fitt, B. D. L., Inman, A. J., Lacey, M. E., and McCartney, H. A. 1992. Splash dispersal of spores of Pseudocercosporella capsellae (white leaf spot) from oilseed rape leaves of different inclination, flexibility and age. J. Plant Dis. Prot. 99:234-244.

4. Fitt, B. D. L., and McCartney, H. A. 1985. Spore dispersal in splash droplets. Pages 87-104 in: Water, Fungi and Plants. P. G. Ayres and L. Boddy, eds. Cambridge University Press, Cambridge.

5. Fitt, B. D. L., and McCartney, H. A. 1986. Spore dispersal in relation to epidemic models. Pages 311-345 in: Disease Spread. Kluwer Academic Publishers, Dordrecht, the Netherlands.

6. Fitt, B. D. L., McCartney, H. A., and Walklate, P. J. 1989. The role of rain in dispersal of pathogen inoculum. Annu. Rev. Phytopathol. 27:241-270.

7. Fitt, B. D. L., Walklate, P. J., McCartney, H. A., Bainbridge, A., Creighton, N. F., Hirst, J. M., Lacey, M. E., and Legg, B. J. 1986. A raintower and wind tunnel for studying the dispersal of plant pathogens by rain and wind. Ann. Appl. Biol. 109:661-671.

8. Macdonald, O. C., and McCartney, H. A. 1989. Calculation of splash droplet trajectories. Agric. For. Meteorol. 39:95-110.

9. Madden, L. V. 1992. Rainfall and the dispersal of fungal spores. Adv. Plant Pathol. 8:39-79.

10. Madden, L. V., Wilson, L. L., and Ellis, M. A. 1993. Field spread of anthracnose fruit rot of strawberry in relation to ground cover and ambient weather conditions. Plant Dis. 77:861-866.

11. Madden, L. V., Wilson, L. L., Yang, X., and Ellis, M. A. 1992. Splash dispersal of Colletotrichum acutatum and Phytophthora cactorum by short-duration simulated rains. Plant Pathol. 41:427-436.

12. Madden, L. V., Yang, X., and Wilson, L. L. 1996. Effects of rain intensity on splash dispersal of Colletotrichum acutatum. Phytopathology 86 : 864-874.

13. Mood, A. M., Graybill, F. A., and Boes, D. C. 1950. Introduction to the Theory of Statistics. McGraw-Hill, Inc., Singapore.

14. Ntahimpera, N., Ellis, M. A., Wilson, L. L., and Madden, L. V. 1998. Effects of a cover crop on splash dispersal of Colletotrichum acutatum conidia. Phytopathology 88:536-543.

15. Othmer, H. G., Dunbar, S. R., and Alt, W. 1988. Models of dispersal in biological systems. J. Math. Biol. 26:263-298.

16. Pielaat, A., and van den Bosch, F. 1998. A model for dispersal of plant pathogens by rain splash. IMA (Inst. Math. Appl.) J. Math. Appl. Biol. 
Med. 15:117-134.

17. Reynolds, K. M., Bulger, M. A., Madden, L. V., and Ellis, M. A. 1987. New methods using simulated rain to study the splash dispersal of plant pathogens. Phytopathology 77:921-926.

18. Seber, G. A. F., and Wild, C. J. 1989. Nonlinear Regression. John Wiley $\&$ Sons, Inc., New York

19. Yang, X., and Madden, L. V. 1993. Effect of ground cover, rain intensity and strawberry plants on splash of simulated raindrops. Agric. For. Meteorol. 65:1-20.
20. Yang, X., Madden, L. V., and Brazee, R. D. 1991. Application of the diffusion equation for modelling splash dispersal of point-source pathogens. New Phytol. 118:295-301.

21. Yang, X., Madden, L. V., Reichard, D. L., Fox, R. D., and Ellis, M. A. 1991. Motion analysis of drop impaction on a strawberry surface. Agric. For. Meteorol. 56:67-92.

22. Yang, X., Madden, L. V., Wilson, L. L., and Ellis, M. A. 1990. Effect of surface topography and rain intensity on splash dispersal of Colletotrichum acutatum. Phytopathology 80:1115-1120. 